\title{
Polyunsaturated fatty acids are potent openers of human M-channels expressed in Xenopus laevis oocytes
}

\author{
Sara Liin, Urban Karlsson, B. H. Bentzen, N. Schmitt and Fredrik Elinder \\ Journal Article
}

\section{Tweet}

N.B.: When citing this work, cite the original article.

Original Publication:

Sara Liin, Urban Karlsson, B. H. Bentzen, N. Schmitt and Fredrik Elinder, Polyunsaturated fatty acids are potent openers of human M-channels expressed in Xenopus laevis oocytes, Acta Physiologica, 2016. 218(1), pp.28-37.

http://dx.doi.org/10.1111/apha.12663

Copyright: Wiley: 12 months

http://eu.wiley.com/WileyCDA/

Postprint available at: Linköping University Electronic Press

http://urn.kb.se/resolve?urn=urn:nbn:se:liu:diva-133537

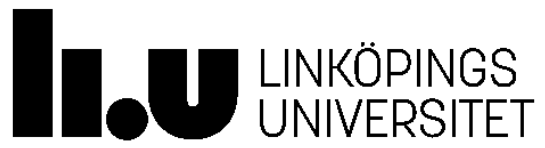




\section{Polyunsaturated fatty acids are potent openers of human}

\section{M-channels expressed in Xenopus laevis oocytes}

Sara I Liin ${ }^{1}$, Urban Karlsson ${ }^{1}$, Bo Hjorth Bentzen ${ }^{2}$, Nicole Schmitt ${ }^{2}$ and Fredrik Elinder ${ }^{1}$

${ }^{1}$ Department of Clinical and Experimental Medicine, Linköping University, Sweden

${ }^{2}$ Danish National Research Foundation Centre for Cardiac Arrhythmia and Department of Biomedical Sciences, University of Copenhagen, Denmark

Corresponding authors: Fredrik Elinder or Sara I Liin, Department of Clinical and Experimental Medicine, Linköping University, SE-581 85 Linköping, Sweden. +46 (0)10 103 8945. fredrik.elinder@liu.se or sara.liin@liu.se.

Short title: Fatty acids open the M-channel 


\section{Abstract}

Aim: Polyunsaturated fatty acids have been reported to reduce neuronal excitability, in part by promoting inactivation of voltage-gated sodium and calcium channels. Effects on neuronal potassium channels are less explored and experimental data ambiguous. The aim of this study was to investigate anti-excitable effects of polyunsaturated fatty acids on the neuronal Mchannel, important for setting the resting membrane potential in hippocampal and dorsal root ganglion neurons.

Methods: Effects of fatty acids and fatty-acid analogues on mouse dorsal root ganglion neurons and on the human $\mathrm{K}_{\mathrm{V}} 7.2 / 3$ channel expressed in Xenopus laevis oocytes were studied using electrophysiology.

Results: Extracellular application of physiologically relevant concentrations of the polyunsaturated fatty acid docosahexaenoic acid hyperpolarized the resting membrane potential $(-2.4 \mathrm{mV}$ by $30 \mu \mathrm{M})$ and increased the threshold current to evoke action potentials in dorsal root ganglion neurons. The polyunsaturated fatty acids docosahexaenoic acid, $\alpha-$ linolenic acid, and eicosapentaenoic acid facilitated opening of the human M-channel, comprised of the heteromeric human $\mathrm{K}_{\mathrm{V}} 7.2 / 3$ channel expressed in Xenopus oocytes, by shifting the conductance-versus-voltage curve towards more negative voltages (by -7.4 to $-11.3 \mathrm{mV}$ by $70 \mu \mathrm{M})$. Uncharged docosahexaenoic acid methyl ester and monounsaturated oleic acid did not facilitate opening of the human $\mathrm{K}_{\mathrm{V}} 7.2 / 3$ channel.

Conclusions: These findings suggest that circulating polyunsaturated fatty acids, with a minimum requirement of multiple double bonds and a charged carboxyl group, dampen excitability by opening neuronal M-channels. Collectively, our data bring light to the molecular targets of polyunsaturated fatty acids and thus a possible mechanism by which polyunsaturated fatty acids reduce neuronal excitability. 
Keywords: electrophysiology, epilepsy, excitability, KCNQ, M-channel, polyunsaturated fatty acids 


\section{Introduction}

Polyunsaturated fatty acids (PUFAs) have been reported to reduce neuronal excitability (Taha et al. 2010a). PUFAs increase seizure thresholds (Voskuyl et al. 1998; Xiao \& Li 1999; Taha et al. 2010b; Bandero et al. 2013; Taha et al. 2013) and pain thresholds (Yehuda et al. 1993; Nakamoto et al. 2010) in rats and mice, and reduce neuronal excitability in vitro (Xiao \& Li 1999; Young et al. 2000). These effects of PUFAs in cellular and animal studies indicate that PUFAs may protect against hyperexcitability in epilepsy and pain. We and others have suggested that PUFAs contribute to the dampening effect of the fat-rich ketogenic diet (Cunnane et al. 2002; Xu et al. 2008), in which the serum concentration of PUFAs is increased 4-fold (Fraser et al. 2003). However, clinical studies on neuronal effects of PUFAs have produced conflicting results, possibly because of different administration times and doses (Taha et al. 2010a). To unveil the neuronal targets of PUFAs is critical both to understand PUFAs' anti-excitable mechanism, and to design future anti-convulsants and analgesics that mimic the PUFA effect and induce reliable clinical anti-excitable effects.

The effect of PUFA on excitability may be mediated by effects on ion channels central for neuronal excitability (Boland \& Drzewiecki 2008). For instance, PUFAs inactivate neuronal

voltage-gated $\mathrm{Na}^{+}$and $\mathrm{Ca}^{2+}$ channels (Vreugdenhil et al. 1996; Hong et al. 2004), and thereby dampen neuronal activity. Despite the important role of $\mathrm{K}^{+}$channels for excitability, the effect of PUFAs on neuronal voltage-gated $\mathrm{K}^{+}\left(\mathrm{K}_{\mathrm{V}}\right)$ channels is less explored and has shown ambiguous results (Gubitosi-Klug et al. 1995; Villarroel \& Schwarz 1996; Holmqvist et al. 2001; Boland \& Drzewiecki 2008). 
The M-current is a sustained $\mathrm{K}^{+}$current at sub-threshold potentials and is therefore important for setting the negative resting membrane potential of, for instance, hippocampal and dorsal root ganglion (DRG) neurons (Jentsch 2000; Brown \& Passmore 2009). At the molecular basis, the M-current conducting channel consists of heteromeric $\mathrm{K}_{\mathrm{V}} 7.2$ and $\mathrm{K}_{\mathrm{V}} 7.3$ subunits encoded by $K C N Q 2$ and $K C N Q 3$ (Wang et al. 1998). These $\mathrm{K}_{\mathrm{V}}$ subunits are expressed in many neuronal types, both excitatory and inhibitory neurons (Cooper et al. 2001), and in several sub-cellular localizations (Devaux et al. 2004). Although the role of M-channels for cellular and network excitability is complex (Vervaeke et al. 2006), the most common effect of M-channel activity is reduced neuronal excitability (Brown \& Passmore 2009). This is supported by loss-of-function mutations in $K C N Q 2$ and $K C N Q 3$ that cause benign familial neonatal seizures (reviewed in Maljevic et al. 2008). Moreover, M-channel openers are anticonvulsant and analgesic (Maljevic et al. 2008; Grunnet et al. 2014).

Arachidonic acid (Schweitzer et al. 1990; Behe et al. 1992; Villarroel 1994; Yu 1995) and other PUFAs (Behe et al. 1992) increase the M-current. PUFA effects on the M-current are however complex. For instance, arachidonic acid-induced increase of M-current was suggested to be mediated by downstream oxygenase metabolites and not by arachidonic acid itself (Schweitzer et al. 1990; Yu 1995), while the effect of other PUFAs, not metabolized by oxygenases, seems to be mediated by the PUFAs themselves (Behe et al. 1992). PUFA effects also tend to vary with time and from cell to cell in cells with native M-channel expression (Behe et al. 1992).

We hypothesized that PUFAs dampen neuronal excitability by directly acting on neuronal Mchannels, and hence investigated the effect of PUFAs on mouse DRG neurons endogenously 
expressing the $\mathrm{M}$-channel, and on the isolated heteromeric $\mathrm{K}_{\mathrm{V}} 7.2 / \mathrm{K}_{\mathrm{V}} 7.3$ channel expressed in Xenopus laevis oocytes. We focused on the marine omega-3 (n-3) PUFA docosahexaenoic acid (DHA), because DHA is one of the most abundant PUFAs in the central nervous system (Taha et al. 2010a), and found that DHA on the M-channel is the most potent electrostatic $\mathrm{K}^{+}-$ channel opener described. 


\section{Material and Methods}

The study conforms with: (Persson 2015).

\section{Patch-clamp on dorsal root ganglion neurons}

Seven 7-12 week-old C57BL/6 mice (Scanbur, Denmark) were used. DRG neurons were dissected and cultured for 1-2 days as previously described (Ottosson et al. 2015). Recordings were done at room temperature in whole-cell current-clamp mode. The intracellular solution contained (in mM): $120 \mathrm{~K}$-gluconate, $10 \mathrm{KCl}, 1$ EGTA, 10 HEPES, 4 Mg-ATP, 0.3 Na-GTP, pH 7.3. The extracellular solution contained (in $\mathrm{mM}$ ): $144 \mathrm{NaCl}, 2.5 \mathrm{KCl}, 10 \mathrm{HEPES}, 0.5$ $\mathrm{MgCl}_{2}, 2 \mathrm{CaCl}_{2}, 10$ glucose, $\mathrm{pH}$ 7.4. Pipettes were of borosilicate glass and had a resistance of 3-6 M $\Omega$. Small and medium sized DRG neurons were selected. DHA or DHA methyl ester was applied for 90 to $120 \mathrm{~s}$ using a pressurized, automated OctaFlow perfusion system (ALA Scientific Instruments, NY, USA). Action potentials were evoked by 50-ms depolarizing pulses from 0.02 to $2 \mathrm{nA}$ in steps of 0.02 to $0.1 \mathrm{nA}$ and the threshold current needed to evoke the first action potential was determined. A liquid-junction potential of $-14 \mathrm{mV}$ was corrected for.

\section{Two-electrode voltage clamp on Xenopus laevis oocytes}

Xenopus laevis oocytes were isolated and maintained as previously described (Bentzen et al. 2006). $\mathrm{K}_{\mathrm{V}} 7.2$ and $\mathrm{K}_{\mathrm{V}} 7.3$ cRNAs were mixed in a 1:1 molar ratio before injection of $50 \mathrm{nl}$ RNA (approximately $1.5 \mathrm{ng}$ of human (h) KV7.2 (GenBank Acc.No. NM_004518) and $1.5 \mathrm{ng}$ of hK 7.3 (NM_004519) into oocytes. This channel will hereafter be referred to as the $\mathrm{hK}_{\mathrm{V}} 7.2 / 3$ channel. For the KCNE co-expression experiments, approximately $1.5 \mathrm{ng}$ of $\mathrm{hK}_{\mathrm{V}} 7.2$ 
and $1.5 \mathrm{ng}$ of $\mathrm{hK}_{\mathrm{V}} 7.3$ were co-injected with $1 \mathrm{ng}$ cRNA coding for hKCNE1 (NM_000219) or hKCNE2 (NM_172201) into each oocyte. Experiments were conducted 2-5 days after injection at room temperature with two-electrode voltage-clamp, as previously described (Liin et al. 2015a). The control solution contained (in mM): $88 \mathrm{NaCl}, 1 \mathrm{KCl}, 15 \mathrm{HEPES}, 0.4 \mathrm{CaCl}_{2}$, and $0.8 \mathrm{MgCl}_{2}, \mathrm{pH}$ to 7.4 . The holding potential was generally $-80 \mathrm{mV}$ with test voltages ranging -110 and $+60 \mathrm{mV}$ ( $2 \mathrm{~s}$ durations, $10 \mathrm{mV}$ increments), and tail currents were measured at $-30 \mathrm{mV}$.

\section{Test compounds}

4,7,10,13,16,19-all-cis-docosahexaenoic acid (DHA), 4,7,10,13,16,19-all-cisdocosahexaenoic acid methyl ester (DHA methyl ester), 5,8,11,14,17-all-cis-eicosapentaenoic acid (EPA), 9,12,15-all-cis-octadecatrienoic acid (ALA), and methyl 9-cis-octadecenoic acid (oleic acid) were from Sigma-Aldrich (Stockholm, Sweden). Fatty acids and methyl ester were handled as previously described (Börjesson et al. 2010).

\section{Electrophysiological analysis}

To quantify the effects on the conductance versus voltage, $G(V)$, curve in Xenopus oocytes, tail currents (14 ms after repolarization) were plotted against the test voltage. The following Boltzmann-like expression was fitted to the data

$$
G(V)=A /\left(1+\exp \left(\left(V_{1 / 2}-V\right) / s\right)\right)^{4},
$$


where $V_{1 / 2}$ is the midpoint and $s$ the slope factor (shared for control and test compound). $V_{1 / 2}$ values were compared to quantify the shift in $G(V)\left(\Delta V_{1 / 2}\right)$. For illustrative clarity in the figures, the curves are normalized between 0 and 1 and the data points connected by lines.

To quantify the concentration dependence of the DHA-induced $\Delta V_{1 / 2}$, the following equation was used:

$$
\Delta V_{1 / 2}=\Delta V_{1 / 2 \max } /\left(1+\left(c_{1 / 2} / c\right)^{n \mathrm{H}}\right)
$$

where $\Delta V_{1 / 2 \max }$ is the maximal shift, $c_{1 / 2}$ the concentration causing $50 \%$ of the maximal shift, $c$ the concentration of DHA (or $\mathrm{H}^{+}$), and $n_{\mathrm{H}}$ is the Hill coefficient.

\section{Statistical analysis}

Average values are expressed as mean $\pm \mathrm{SEM}$. Mean values for $\Delta V_{\mathrm{m}}, \Delta V_{1 / 2}$ and relative firing threshold were analyzed by a two-tailed one sample $t$-test where mean values were compared with a hypothetical value of 0 ( 1 for firing threshold). Following washout, recovery of the DHA effect was analyzed using a two-tailed paired $t$-test. DHA effects on the $\mathrm{hK}_{\mathrm{V}} 7.2 / 3$ channel, with and without KCNE subunits were compared using one-way ANOVA and Bonferroni's Multiple Comparison Test. $\mathrm{P} \leq 0.05$ is considered significant. 


\section{Results}

\section{DHA hyperpolarizes DRG neurons and affects firing properties}

To study the effect of PUFAs on excitability of neurons, we employed the marine omega-3 PUFA DHA (Fig. 1a). We added DHA to DRG neurons from mice and measured the effect on the resting membrane potential $\left(V_{\mathrm{m}}\right)$ using the patch-clamp technique. The mean resting $V_{\mathrm{m}}$ was $-69.1 \pm 2.1 \mathrm{mV}(n=12)$. In nine out of $12 \mathrm{DRG}$ neurons, $30 \mu \mathrm{M}$ DHA quickly hyperpolarized the resting $V_{\mathrm{m}}$ (Fig. 1b). The mean DHA-induced shift in resting $V_{\mathrm{m}}$ in these neurons was $-2.4 \pm 0.3 \mathrm{mV}(n=9, \mathrm{P}=<0.0001)$. This hyperpolarization was reversed when $10 \mu \mathrm{M}$ of the M-channel blocker XE991 was applied in the presence of DHA (Fig. 1b; $\Delta V_{\mathrm{m}}=$ $+2.7 \pm 0.7 \mathrm{mV}$, compared to $30 \mu \mathrm{M}$ DHA, $n=9, \mathrm{P}=0.0065$; resting $V_{\mathrm{m}}$ in the presence of $\mathrm{DHA}+\mathrm{XE991}$ is not significantly different from the control resting $V_{\mathrm{m}}, \mathrm{P}=0.8$ with paired ttest). The effect of XE991 on resting $V_{\mathrm{m}}$ was similar to previous reports using sensory neurons (Wladyka et al. 2008; Du et al. 2014). In a subset of DRG neurons (three out of 12), $30 \mu \mathrm{M}$ DHA induced a depolarization of the resting $V_{\mathrm{m}}$ by $+1,+3$ and $+3 \mathrm{mV}$, respectively.

To investigate the DHA effect on the firing properties in DRG neurons, we evoked action potentials in six DRG neurons by using constant depolarizing current pulses of different amplitudes, and applied $30 \mu \mathrm{M}$ DHA. Upon DHA application, the resting $V_{\mathrm{m}}$ was hyperpolarized (Fig. 1c) in all six neurons (by -0.5 to $-4 \mathrm{mV}$ ). Furthermore, the threshold current to evoke action potentials was increased (Fig. 1c) in all six neurons; in two of the neurons, action potentials could not be evoked in the presence of DHA and in the remaining four, $30 \mu \mathrm{M}$ DHA increased the threshold current by a factor of $1.29 \pm 0.06(n=4, \mathrm{P}=0.02)$. The DHA effects in DRG neurons had slow and incomplete recovery upon perfusion with 
control solution. In summary, DHA exerts a dampening effect on the excitability of DRG neurons, presumably through an augmentation of the M-current.

\section{DHA and EPA facilitate opening of the $h K_{V} 7.2 / 3$ channel expressed in Xenopus oocytes}

To study the effect of DHA on the isolated M-channel, we co-expressed human $\mathrm{K}_{\mathrm{V}} 7.2$ and $\mathrm{K}_{\mathrm{V}} 7.3$ subunits in Xenopus laevis oocytes to form heteromeric $\mathrm{hK}_{\mathrm{V}} 7.2 / 3$ channels. In line with DHA-induced augmentation of the M-current, extracellular application of $70 \mu \mathrm{M}$ DHA shifted the $G(V)$ curve of the $\mathrm{hK}_{\mathrm{V}} 7.2 / 3$ channel towards more negative voltages (Fig. 2a-b; $\left.\Delta V_{1 / 2}=-9.3 \pm 1.7 \mathrm{mV}, n=5, \mathrm{P}=0.005\right)$. Similar to $\mathrm{DRG}$ neurons, the onset of the DHA effect in Xenopus oocytes was quick (inset in Fig. 2b). DHA concentrations of $7 \mu \mathrm{M}$ and higher induced significant $G(V)$ shifts and $50 \%$ of the maximum $G(V)$ shift was achieved by $10.2 \pm 5.5 \mu \mathrm{M}$ DHA (Fig. 2c). $70 \mu \mathrm{M}$ DHA had no significant effect on the maximum conductance $(\mathrm{P}=0.7$ with paired t-test, $n=5)$. For $70 \mu \mathrm{M}$ DHA, the recovery of $\Delta V_{1 / 2}$ was 52 $\pm 8 \%$ after washing with a control solution supplemented with $100 \mathrm{mg} / \mathrm{L}$ albumin. To test whether the ability to facilitate the $\mathrm{hK}_{\mathrm{V}} 7.2 / 3$-channel opening was unique to DHA or applicable also to other PUFAs, we tested the effect of the PUFAs $\alpha$-linolenic acid and eicosapentaenoic acid (ALA and EPA respectively, Fig. 1a). ALA and EPA induced a similar $G(V)$ shift as DHA: $70 \mu \mathrm{M}$ ALA and EPA shifted the $G(V)$ curve of the $\mathrm{hK}_{\mathrm{V}} 7.2 / 3$ channel by $-7.4 \pm 0.5 \mathrm{mV}(n=5, \mathrm{P}=0.0001)$ and $-11.3 \pm 1.2 \mathrm{mV}(n=4, \mathrm{P}=0.003)$, respectively (Fig. 2d-e).

PUFA methyl ester and monounsaturated fatty acid do not affect the $h K_{V} 7.2 / 3$ channel expressed in Xenopus oocytes 
Previous studies have given contradicting results on whether uncharged DHA analogues dampen neuronal firing (Xiao \& Li 1999; Taha et al. 2013). The structure of the uncharged DHA methyl ester is identical to the structure of DHA, except that the DHA methyl ester has a methyl group coupled to the carboxyl group, which renders the molecule uncharged (Fig. 1a). In contrast to DHA, $70 \mu \mathrm{M}$ DHA methyl ester did not facilitate the opening of the $\mathrm{hK}_{\mathrm{V}} 7.2 / 3$ channel expressed in Xenopus oocytes (Fig. 3a-b; $\Delta V_{1 / 2}=-1.0 \pm 0.5 \mathrm{mV}, n=4, \mathrm{P}=$ 0.1). Likewise, it did not open M-channels to hyperpolarize DRG neurons; in two out of seven DRG neurons tested, $30 \mu \mathrm{M}$ DHA methyl ester slowly induced a depolarization of the resting $V_{\mathrm{m}}$ by +2 and $+3 \mathrm{mV}$, respectively, and in the remaining five cells, $30 \mu \mathrm{M}$ DHA methyl ester had no effect on the resting $V_{\mathrm{m}}(-0.5 \pm 0.3 \mathrm{mV}(n=5, \mathrm{P}=0.2))$.

The lack of effect of the DHA methyl ester on $V_{1 / 2}$ of the $h K_{V} 7.2 / 3$ channel may be because a charged moiety of the fatty acid is required to affect the $\mathrm{hK}_{\mathrm{V}} 7.2 / 3$ channel, as has previously been suggested for the related $\mathrm{hK}_{\mathrm{V}} 7.1$ channel and the Drosophila Shaker $\mathrm{K}^{+}$channel (Börjesson et al. 2010; Liin et al. 2015a). If the negative charge of the carboxyl head of DHA is critical to facilitate the $\mathrm{hK}_{\mathrm{V}} 7.2 / 3$ channel opening, we would expect the DHA effect to depend on carboxyl charge protonation, and thus to be $\mathrm{pH}$ dependent. To test this hypothesis, we measured the ability of DHA to facilitate $\mathrm{hK}_{\mathrm{V}} 7.2 / 3$ channel opening in extracellular $\mathrm{pH}$ ranging from 6.5 to 10 ; the DHA-induced $G(V)$ shift of the $\mathrm{hK}_{\mathrm{V}} 7.2 / 3$ channel was enhanced at high pH (Fig. 3c; $\Delta V_{1 / 2}$ at $\left.\mathrm{pH} 9=-24.7 \pm 3.9 \mathrm{mV}, n=8, \mathrm{P}=0.0004\right)$, in which a large fraction of DHA molecules are deprotonated and negatively charged. In contrast, the ability of DHA to shift the $G(V)$ of the $\mathrm{hK}_{\mathrm{V}} 7.2 / 3$ channel was abolished at $\mathrm{pH} 6.5$ (Fig. 3d; $\Delta V_{1 / 2}$ at $\mathrm{pH}$ $6.5=-0.8 \pm 0.8 \mathrm{mV}, n=3, \mathrm{P}=0.4)$, in which a large fraction of DHA molecules are protonated and uncharged. The $\mathrm{pH}$-response relationship for $70 \mu \mathrm{M}$ DHA is summarized in Figure 3e. 
Previous studies have also provided contradicting indications on whether only PUFAs dampen excitability or if also monounsaturated fatty acids act anti-excitable (Bendahhou et al. 1997; Voskuyl et al. 1998; Hong et al. 2004; Taha et al. 2010b; Bandero et al. 2013; Taha et al. 2013). Oleic acid (Fig. 1a) is an abundant monounsaturated fatty acid in the nervous system (Fraser et al. 2003). Oleic acid has identical acyl chain length to ALA (18 carbons) but is lacking two of the double bonds present in ALA. In contrast to the three tested PUFAs, 70 $\mu \mathrm{M}$ monounsaturated oleic acid did not facilitate the opening of the $h K_{\mathrm{V}} 7.2 / 3$ channel expressed in Xenopus oocytes (Fig. 3f-g; $\Delta V_{1 / 2}=+0.4 \pm 0.5 \mathrm{mV}, n=4, \mathrm{P}=0.5$ ).

\section{KCNE co-expression does not alter DHA sensitivity of the $h K_{V} 7.2 / 3$}

\section{channel expressed in Xenopus oocytes}

Auxiliary KCNE $\beta$-subunits are critical for proper cardiac and epithelial function of the related $\mathrm{K}_{\mathrm{V}}$ 7.1 channel (Liin et al. 2015b). KCNE subunits are widely distributed and also expressed in the nervous system (McCrossan \& Abbott 2004). KCNEs have therefore been speculated to be regulatory subunits of the native M-channel. For instance, mRNA expression patterns of KCNE2, $\mathrm{K}_{\mathrm{V}} 7.2$ and $\mathrm{K}_{\mathrm{V}} 7.3$ are largely similar in the mouse brain (Tinel et al. 1998; Tinel et al. 2000). It remains however to be determined whether the $\mathrm{K}_{\mathrm{V}} 7.2 / 3$ channel and KCNE subunits form functional neuronal complexes in vivo. PUFA effects on the $\mathrm{hK}_{\mathrm{V}} 7.1$ channel are altered by KCNE co-expression (Liin et al. 2015a; Moreno et al. 2015). We therefore tested whether KCNE co-expression altered PUFA effects on the $h K_{V} 7.2 / 3$ channel. For these experiments, $\mathrm{hK}_{\mathrm{V}} 7.2 / 3$ was co-expressed with either hKCNE1 or hKCNE2 in Xenopus oocytes because these KCNE subunits have previously been shown to modulate the activity of $\mathrm{K}_{\mathrm{V}} 7.2 / 3$ in heterologous expression systems (Yang et al. 1998; Tinel et al. 2000). 
In line with previous reports (Yang et al. 1998; Tinel et al. 2000), co-expression of $\mathrm{hK}_{\mathrm{V}} 7.2 / 3$ and hKCNE1 generated currents with slowed activation kinetics (Fig. 4a) while co-expression of $\mathrm{hK}_{\mathrm{V}} 7.2 / 3$ and hKCNE2 generated fairly $\mathrm{hK}_{\mathrm{V}} 7.2 / 3$-like currents (Fig. $\left.4 \mathbf{c}\right)$.

$\mathrm{hK}_{\mathrm{V}} 7.2 / 3+\mathrm{hKCNE} 1$ currents were contaminated by currents likely generated by endogenous $\mathrm{K}_{\mathrm{V}} 7.1$ and injected $\mathrm{hKCNE} 1$ at depolarized voltages (Yang et al. 1998), at which the $\mathrm{K}_{\mathrm{V}} 7.1 / \mathrm{KCNE} 1$ channel is active. Therefore, currents generated by voltage steps more positive than $0 \mathrm{mV}$ were discarded in our analysis of $\mathrm{hK}_{\mathrm{V}} 7.2 / 3+\mathrm{hKCNE} 1$. As for $\mathrm{hK}_{\mathrm{V}} 7.2 / 3$ alone, 70 $\mu \mathrm{M}$ DHA increased $\mathrm{hK}_{\mathrm{V}} 7.2 / 3+\mathrm{hKCNE} 1$ and $\mathrm{hK}_{\mathrm{V}} 7.2 / 3+\mathrm{hKCNE} 2$ current amplitude at negative voltages and shifted the $G(V)$ curve towards more negative voltages (Fig. 4a-d; for hKCNE1: $\Delta V_{1 / 2}=-8.2 \pm 2.3 \mathrm{mV}, n=4, \mathrm{P}=0.04$; for hKCNE2: $\Delta V_{1 / 2}=-4.6 \pm 0.5 \mathrm{mV}, n=5$, $\mathrm{P}=0.0006$ ). Thus, co-expression of $\mathrm{hK}_{\mathrm{V}} 7.2 / 3$ with $\mathrm{hKCNE} 1$ or hKCNE2 in Xenopus oocytes did not significantly alter the ability of DHA to facilitate opening of the $h K_{V} 7.2 / 3$ channel (P $>0.05$ with ANOVA). 


\section{Discussion}

In this study, we provide evidence that PUFAs open neuronal M-channels, thereby dampening neuronal excitability. We found that DHA hyperpolarized the resting membrane potential of DRG neurons and increased the firing threshold current in these neurons. The PUFAs DHA, ALA, and EPA facilitated opening of the $\mathrm{hK}_{\mathrm{V}} 7.2 / 3$ channel (=M-channel) expressed in Xenopus oocytes by shifting the $G(V)$ curve towards more negative voltages. In contrast to the facilitating effects found for PUFAs, the uncharged PUFA analogue DHA methyl ester and the monounsaturated oleic acid were ineffective on the M-channel expressed in Xenopus oocytes. DHA methyl ester also failed to hyperpolarize the resting membrane potential of DRG neurons. Co-expression of KCNE1 or KCNE2 did not significantly alter the DHA effect on the M-channel.

The concentration of free PUFAs in serum, and likely in cerebrospinal fluid, is around 10-50 $\mu \mathrm{M}$, but may be as high as $135 \mu \mathrm{M}$ (Conquer \& Holub 1998; Fraser et al. 2003; Brouwer et al. 2006). The majority of the circulating 'free' PUFA is expected to be bound to serum albumin (Cistola \& Small 1991). Cellular membranes however compete with albumin for fatty acid binding (Cistola \& Small 1991). Some membranes even have specific fatty acidbinding proteins that facilitate the uptake of fatty acids (van der Vusse 2009). Under conditions with elevated serum PUFAs, as seen during ketogenic-diet treatment, the fraction of PUFAs associated with cellular membranes increases dramatically (Cistola \& Small 1991). The albumin concentration in cerebrospinal fluid is considerable lower than in serum (Seyfert et al. 2004). This complex interplay between PUFAs and proteins/membranes makes it hard to estimate how much of the circulating free PUFAs that are available to affect peripheral and central neurons and to determine what physiological PUFA concentration to relate our work 
to. For simplicity, we therefore assume that most of the free circulating PUFAs are available to affect neurons.

In this work, we found that $30 \mu \mathrm{M}$ DHA hyperpolarized the resting membrane potential of DRG neurons by $-2.4 \mathrm{mV}$ and shifted the $G(V)$ curve of the M-channel in Xenopus oocytes by $-9 \mathrm{mV}$ (deduced from Fig. 2c). Previous computer simulations suggest that quantitatively similar small alterations $(-1$ to $-5 \mathrm{mV})$ in the resting membrane potential of neurons (Tigerholm et al. 2012) and in the voltage dependence of ion channels (Thomas et al. 2009; Tigerholm et al. 2012) are effective means to reduce neuronal excitability and prevent epileptic activity. These computer simulations in combination with our experimental findings in DRG neurons and on isolated M-channels suggest that PUFA-induced augmentation of the M-current contributes to the anti-excitable effect of PUFAs. This is further supported by a comparison of the PUFA effects found in the present work and previously reported effects of the clinically approved M-channel opener retigabine; the PUFA effects on the resting membrane potential and the firing threshold in DRG neurons, and on the voltage dependence of the isolated human M-channel expressed in Xenopus oocytes are, on the whole, similar to, but quantitatively smaller than, the effect of retigabine (Main et al. 2000; Zheng et al. 2013; Du et al. 2014). Our finding that DHA methyl ester and oleic acid were ineffective suggests that possible anti-excitable effects of PUFA methyl esters and monounsaturated fatty acids are not mediated via the M-channel. In a subset of DRG neurons, we found that DHA instead depolarized the resting membrane potential, which would tend to increase excitability. Speculatively, this depolarization may be caused by DHA-induced activation of TRPV1 (Matta et al. 2007), which is expressed in small to medium sized DRG neurons (Caterina et al. 1997). 
We have previously reported that PUFAs facilitate opening of the $\mathrm{hK}_{\mathrm{V}} 7.1$ channel (when not co-expressed with the KCNE1 $\beta$-subunit) and of the Shaker $\mathrm{K}_{\mathrm{V}}$ channel, by shifting the $G(V)$ of these channels towards more negative voltages (Xu et al. 2008; Börjesson et al. 2010; Liin et al. 2015a). In similarity to the M-channel findings reported here, PUFA methyl ester and monounsatured fatty acid were ineffective on those channels. The resemblance in PUFA modulation of these three $\mathrm{K}_{\mathrm{V}}$ channels implies a general PUFA binding site and mechanism of action for PUFA-induced augmentation. Thus, PUFAs represent a principally new mechanism for M-channel opening compounds: We have previously suggested PUFAs to interact with the outermost gating charges (positively charged arginines) of the voltage sensor S4 (the fourth transmembrane segment of an ion channel subunit) in $K_{V}$ channels at the interface between the lipid bilayer and the voltage-sensor domain (S1-S4) (Börjesson \& Elinder 2011; Ottosson et al. 2014; Liin et al. 2015a; Yazdi et al. 2016). In contrast, other Mchannel openers are suggested to bind to the central core of the voltage-sensor domain (Padilla et al. 2009; Peretz et al. 2010; Li et al. 2013), or to the pore domain (S5-S6) (Xiong et al. 2007; Lange et al. 2009). However, it should be noted that DHA is much more potent on the M-channel than on the previously investigated $\mathrm{K}_{\mathrm{V}}$ channels expressed in Xenopus oocytes; the DHA concentration needed to shift the $G(V)$ by $-3 \mathrm{mV}$ (in $\mathrm{pH} 7.4$ ) is only $4 \mu \mathrm{M}$ for the M-channel, while $36 \mu \mathrm{M}$ is needed for the $\mathrm{K}_{\mathrm{V}} 1$-type Shaker channel (Xu et al. 2008), and >70 $\mu \mathrm{M}$ for the cardiac $\mathrm{hK}_{\mathrm{V}} 7.1 / \mathrm{hKCNE} 1$ channel (Liin et al. 2015a). Hence, PUFAs act on Mchannels in a clinically relevant concentration range (Xu et al. 2008; Börjesson et al. 2010; Tigerholm et al. 2012).

We have previously shown that the distribution of charged residues in the extracellular end of S4 impacts PUFA sensitivity of $K_{V}$ channels; additional positive charges offer stronger electrostatic interaction between the PUFA molecule and the channel (Ottosson et al. 2014). 
This can, however, not explain the different DHA sensitivities of $\mathrm{hK}_{\mathrm{V}} 7.2 / 3, \mathrm{hK} \mathrm{V}_{\mathrm{V}} 7.1 / \mathrm{hKCNE} 1$, and Shaker $\mathrm{K}^{+}$channels, because the gating charge profile of the outer end of S4 does not differ between these channels. An alternative explanation is that these channels have different affinities for PUFAs. This is supported by the higher $c_{1 / 2}$ obtained for the Shaker $\mathrm{K}^{+}$channel compared to the $\mathrm{hK}_{\mathrm{V}} 7.2 / 3$ channel $(80 \mu \mathrm{M}$ (Xu et al. 2008) compared to $10 \mu \mathrm{M}$ (Fig. 2c) under identical conditions). The poor DHA sensitivity of the $\mathrm{hK}_{\mathrm{V}} 7.1 / \mathrm{hKCNE} 1$ complex under similar conditions is likely caused by KCNE1-induced protonation of DHA (Liin et al. 2015a). Future work that compares the detailed PUFA binding sites in these channels is required for a molecular understanding of differential PUFA sensitivity and differential impact of KCNE co-expression on PUFA sensitivity in $\mathrm{K}_{\mathrm{V}}$ channels (Liin et al. 2015a; Moreno et al. 2015).

To conclude, our data suggest that the neuronal M-channel is one of the important molecular targets of PUFAs, and that PUFA-induced opening of the M-channel contributes to the antiexcitable effect of PUFAs in the nervous system. Thus, anti-excitable PUFA effects in vitro and in vivo (e.g. Voskuyl et al. 1998; Xiao \& Li 1999) are likely caused by a combination of effects on for instance voltage-gated $\mathrm{Na}^{+}$and $\mathrm{Ca}^{2+}$ (Boland \& Drzewiecki 2008) and the Mchannel (this study). The molecular details of how PUFAs augment the M-current may function as a framework for the design of future M-channel openers to be used in the treatment of epilepsy and pain. 


\section{Acknowledgements}

This work was supported by the Swedish Research Council, the Swedish Heart-Lung

Foundation, the Swedish Brain Foundation, the County Council of Östergötland, and Queen Silvia’s Anniversary Foundation.

\section{Conflict of Interest}

The authors declare no competing financial interests. 


\section{References}

Bandero, C.R., Salvadori, M.G., Gomes, A.T., Dal Ri, N.M., Furian, A.F., Oliveira, M.S., Rambo, L.M., Scorza, F.A., Cysneiros, R.M., Emanuelli, T. \& Mello, C.F. 2013. Fish oil attenuates methylmalonate-induced seizures. Epilepsy Res 105, 69-76.

Behe, P., Sandmeier, K. \& Meves, H. 1992. The effect of arachidonic acid on the M current of NG108-15 neuroblastoma x glioma hybrid cells. Pflugers Arch 422, 120-128.

Bendahhou, S., Cummins, T.R. \& Agnew, W.S. 1997. Mechanism of modulation of the voltage-gated skeletal and cardiac muscle sodium channels by fatty acids. Am J Physiol 272, C592-600.

Bentzen, B.H., Schmitt, N., Calloe, K., Dalby Brown, W., Grunnet, M. \& Olesen S.P. 2006. The acrylamide (S)-1 differentially affects Kv7 (KCNQ) potassium channels. Neuropharmacology 51, 1068-1077.

Boland, L.M. \& Drzewiecki, M.M. 2008. Polyunsaturated fatty acid modulation of voltagegated ion channels. Cell Biochem Biophys 52, 59-84.

Brouwer, I.A., Zock, P.L., Camm, A.J., Bocker, D., Hauer, R.N., Wever, E.F., Dullemeijer, C., Ronden, J.E., Katan, M.B., Lubinski, A., Buschler, H. \& Schouten, E.G. 2006. Effect of fish oil on ventricular tachyarrhythmia and death in patients with implantable cardioverter defibrillators: the Study on Omega-3 Fatty Acids and Ventricular Arrhythmia (SOFA) randomized trial. Jama 295, 2613-2619.

Brown, D.A. \& Passmore, G.M. 2009. Neural KCNQ (Kv7) channels. Br J Pharmacol 156, 1185-1195.

Börjesson, S.I., Parkkari, T., Hammarström, S. \& Elinder, F. 2010. Electrostatic tuning of cellular excitability. Biophys J 98, 396-403.

Börjesson, S.I. \& Elinder, F. 2011. An electrostatic potassium channel opener targeting the final voltage sensor transition. J Gen Physiol 137, 563-577. 
Caterina, M.J., Schumacher, M.A., Tominaga, M., Rosen, T.A., Levine, J.D. \& Julius, D. 1997. The capsaicin receptor: a heat-activated ion channel in the pain pathway. Nature $389,816-824$.

Cistola, D.P. \& Small, D.M. 1991. Fatty acid distribution in systems modeling the normal and diabetic human circulation. J Clin Invest 87, 1431-1441.

Conquer, J.A. \& Holub, B.J. 1998. Effect of supplementation with different doses of DHA on the levels of circulating DHA as non-esterified fatty acid in subjects of Asian Indian background. J Lipid Res 39, 286-292.

Cooper, E.C., Harrington, E., Jan, Y.N. \& Jan, L.Y. 2001. M channel KCNQ2 subunits are localized to key sites for control of neuronal network oscillations and synchronization in mouse brain. J Neurosci 21, 9529-9540.

Cunnane, S.C., Musa, K., Ryan, M.A., Whiting, S. \& Fraser, D.D. 2002. Potential role of polyunsaturates in seizure protection achieved with the ketogenic diet. Prostaglandins Leukot Essent Fatty Acids 67, 131-135.

Devaux, J.J., Kleopa, K.A., Cooper, E.C. \& Scherer, S.S. 2004. KCNQ2 is a nodal K+ channel. J Neurosci 24, 1236-1244.

Du, X., Hao, H., Gigout, S., Huang, D., Yang, Y., Li, L., Wang, C., Sundt, D., Jaffe, D.B., Zhang, H. \& Gamper, N. 2014. Control of somatic membrane potential in nociceptive neurons and its implications for peripheral nociceptive transmission. Pain 155, 23062322.

Fraser, D.D., Whiting, S., Andrew, R.D., Macdonald, E.A., Musa-Veloso, K. \& Cunnane, S.C. 2003. Elevated polyunsaturated fatty acids in blood serum obtained from children on the ketogenic diet. Neurology 60, 1026-1029.

Grunnet, M., Strobaek, D., Hougaard, C. \& Christophersen, P. 2014. Kv7 channels as targets for anti-epileptic and psychiatric drug-development. Eur J Pharmacol 726, 133-137. 
Gubitosi-Klug, R.A., Yu, S.P., Choi, D.W. \& Gross, R.W. 1995. Concomitant acceleration of the activation and inactivation kinetics of the human delayed rectifier $\mathrm{K}+$ channel (Kv1.1) by Ca2+-independent phospholipase A2. J Biol Chem 270, 2885-2888.

Holmqvist, M.H., Cao, J., Knoppers, M.H., Jurman, M.E., Distefano, P.S., Rhodes, K.J., Xie, Y. \& An, W.F. 2001. Kinetic modulation of Kv4-mediated A-current by arachidonic acid is dependent on potassium channel interacting proteins. J Neurosci 21, 4154-4161.

Hong, M.P., Kim, H.I., Shin, Y.K., Lee, C.S., Park, M. \& Song, J.H. 2004. Effects of free fatty acids on sodium currents in rat dorsal root ganglion neurons. Brain Res 1008, 8191.

Jentsch, T.J. 2000. Neuronal KCNQ potassium channels: physiology and role in disease. Nat Rev Neurosci 1, 21-30.

Lange, W., Geissendorfer, J., Schenzer, A., Grotzinger, J., Seebohm, G., Friedrich, T. \& Schwake, M. 2009. Refinement of the binding site and mode of action of the anticonvulsant Retigabine on KCNQ K+ channels. Mol Pharmacol 75, 272-280.

Li, P., Chen, Z., Xu, H., Sun, H., Li, H., Liu, H., Yang, H., Gao, Z., Jiang, H. \& Li, M. 2013. The gating charge pathway of an epilepsy-associated potassium channel accommodates chemical ligands. Cell Res 23, 1106-1118.

Liin, S.I., Silvera Ejneby, M., Barro-Soria, R., Skarsfeldt, M.A., Larsson, J.E., Starck Härlin, F., Parkkari, T., Bentzen, B.H., Schmitt, N., Larsson, H.P. \& Elinder, F. 2015a. Polyunsaturated fatty acid analogs act antiarrhythmically on the cardiac IKs channel. Proc Natl Acad Sci U S A 112, 5714-5719.

Liin, S.I., Barro-Soria, R. \& Larsson, H.P. 2015b. The KCNQ1 channel - remarkable flexibility in gating allows for functional versatility. J Physiol 593, 2605-2615. 
Main, M.J., Cryan, J.E., Dupere, J.R., Cox, B., Clare, J.J. \& Burbidge, S.A. 2000. Modulation of KCNQ2/3 potassium channels by the novel anticonvulsant retigabine. Mol Pharmacol 58, 253-262.

Maljevic, S., Wuttke, T.V. \& Lerche, H. 2008. Nervous system KV7 disorders: breakdown of a subthreshold brake. J Physiol 586, 1791-1801.

Matta, J.A., Miyares, R.L. \& Ahern, G.P. 2007. TRPV1 is a novel target for omega-3 polyunsaturated fatty acids. $J$ Physiol $578,397-411$.

McCrossan, Z.A. \& Abbott, G.W. 2004. The MinK-related peptides. Neuropharmacology 47, 787-821.

Moreno, C., de la Cruz, A., Oliveras, A., Kharche, S.R., Guizy, M., Comes, N., Stary, T., Ronchi, C., Rocchetti, M., Baró, I., Loussouarn, G., Zaza, A., Severi, S., Felipe, A. \& Valenzuela, C. 2015. Marine n-3 PUFAs modulate IKs gating, channel expression, and location in membrane domains. Cardiovasc Res 105, 223-232.

Nakamoto, K., Nishinaka, T., Mankura, M., Fujita-Hamabe, W. \& Tokuyama, S. 2010. Antinociceptive effects of docosahexaenoic acid against various pain stimuli in mice. Biol Pharm Bull 33, 1070-1072.

Ottosson, N.E., Liin, S.I. \& Elinder, F.E. 2014. Drug-induced ion channel opening tuned by the voltage sensor charge profile. J Gen Physiol 143, 173-182.

Ottosson, N.E., Wu, X., Nolting, A., Karlsson, U., Lund, P.-E., Ruda, K., Svensson, S., Konradsson, P. \& Elinder, F. 2015. Resin-acid derivatives as potent electrostatic openers of voltage-gated K channels and suppressors of neuronal excitability. Sci Rep 5, 13278.

Padilla, K., Wickenden, A.D., Gerlach, A.C., McCormack, K. 2009. The KCNQ2/3 selective channel opener ICA-27243 binds to a novel voltage-sensor domain site. Neurosci Lett 465, 138-142. 
Peretz, A., Pell, L., Gofman, Y., Haitin, Y., Shamgar, L., Patrich, E., Kornilov, P., GourgyHacohen, O., Ben-Tal, N. \& Attali, B. 2010. Targeting the voltage sensor of Kv7.2 voltage-gated K+ channels with a new gating-modifier. Proc Natl Acad Sci U S A 107, $15637-15642$.

Persson, P.B. 2015. Good publication practice in physiology 2015. Acta Physiol 215, 163164.

Schweitzer, P., Madamba, S. \& Siggins, G.R. 1990. Arachidonic acid metabolites as mediators of somatostatin-induced increase of neuronal M-current. Nature 346, 464467.

Seyfert, S., Faulstich, A \& Marx, P. 2004. What determines the CSF concentrations of albumin and plasma-derived IgG? J Neurol Sci 219, 31-33.

Taha, A.Y., Burnham, W.M. \& Auvin, S. 2010a. Polyunsaturated fatty acids and epilepsy. Epilepsia 51, 1348-1358.

Taha, A.Y., Jeffrey, M.A., Taha, N.M., Bala, S. \& Burnham, W.M. 2010b. Acute administration of docosahexaenoic acid increases resistance to pentylenetetrazolinduced seizures in rats. Epilepsy Behav 17, 336-343.

Taha, A.Y., Zahid, T., Epps, T., Trepanier, M.O., Burnham, W.M., Bazinet, R.P. \& Zhang, L. 2013. Selective reduction of excitatory hippocampal sharp waves by docosahexaenoic acid and its methyl ester analog ex-vivo. Brain Res 1537, 9-17.

Thomas, E.A., Reid, C.A., Berkovic, S.F. \& Petrou, S. 2009. Prediction by modeling that epilepsy may be caused by very small functional changes in ion channels. Arch Neurol $66,1225-1232$.

Tigerholm, J., Börjesson, S.I., Lundberg, L., Elinder, F. \& Fransen, E. 2012. Dampening of Hyperexcitability in CA1 Pyramidal Neurons by Polyunsaturated Fatty Acids Acting on Voltage-Gated Ion Channels. PLoS One 7, e44388. 
Tinel, N., Lauritzen, I., Chouabe, C., Lazdunski, M. \& Borsotto, M. 1998. The KCNQ2 potassium channel: splice variants, functional and developmental expression. Brain localization and comparison with KCNQ3. FEBS Lett 438, 171-176.

Tinel, N., Diochot, S., Lauritzen, I., Barhanin, J., Lazdunski, M. \& Borsotto, M. 2000. M-type KCNQ2-KCNQ3 potassium channels are modulated by the KCNE2 subunit. FEBS Lett $480,137-141$.

van der Vusse, G.J. 2009. Albumin as fatty acid transporter. Drug Metab Pharmacokinet 24, 300-307.

Vervaeke, K., Gu, N., Agdestein, C., Hu, H. \& Storm, J.F. 2006. Kv7/KCNQ/M-channels in rat glutamatergic hippocampal axons and their role in regulation of excitability and transmitter release. J Physiol 576, 235-256.

Villarroel, A. 1994. On the role of arachidonic acid in M-current modulation by muscarine in bullfrog sympathetic neurons. J Neurosci 14, 7053-7066.

Villarroel, A. \& Schwarz, T.L. 1996. Inhibition of the Kv4 (ShaI) family of transient K+ currents by arachidonic acid. J Neurosci 16, 2522-2532.

Voskuyl, R.A., Vreugdenhil, M., Kang, J.X. \& Leaf, A. 1998. Anticonvulsant effect of polyunsaturated fatty acids in rats, using the cortical stimulation model. Eur J Pharmacol 341, 145-152.

Vreugdenhil, M., Bruehl, C., Voskuyl, R.A., Kang, J.X., Leaf, A. \& Wadman, W.J. 1996. Polyunsaturated fatty acids modulate sodium and calcium currents in CA1 neurons. Proc Natl Acad Sci U S A 93, 12559-12563.

Wang, H.S., Pan, Z., Shi, W., Brown, B.S., Wymore, R.S., Cohen, I.S., Dixon, J.E. \& McKinnon, D. 1998. KCNQ2 and KCNQ3 potassium channel subunits: molecular correlates of the M-channel. Science 282, 1890-1893. 
Wladyka, C.L., Feng, B., Glazebrook, P.A., Schild, J.H. \& Kunze, D.L. 2008. The KCNQ/Mcurrent modulates arterial baroreceptor function at the sensory terminal in rats. $J$ Physiol $586,795-802$.

Xiao, Y. \& Li, X. 1999. Polyunsaturated fatty acids modify mouse hippocampal neuronal excitability during excitotoxic or convulsant stimulation. Brain Res 846, 112-121.

Xiong, Q., Sun, H. \& Li, M. 2007. Zinc pyrithione-mediated activation of voltage-gated KCNQ potassium channels rescues epileptogenic mutants. Nat Chem Biol 3, 287-296.

Xu, X.P., Erichsen, D., Börjesson, S.I., Dahlin, M., Åmark, P. \& Elinder, F. 2008. Polyunsaturated fatty acids and cerebrospinal fluid from children on the ketogenic diet open a voltage-gated K channel: A putative mechanism of antiseizure action. Epilepsy $\operatorname{Res} 80,57-66$.

Yang, W.-P., Levesque, P.C., Little, W.A., Conder, M.L., Ramakrishnan, P., Neubauer, M.G. \& Blanar, M.A. 1998. Functional expression of two KvLQT1-related potassium channels responsible for an inherited idiopathic epilepsy. J Biol Chem 273, 1941919423.

Yazdi, S., Stein, M., Elinder, F., Andersson, M. \& Lindahl, E. 2016. The molecular basis of polyunsturated fatty acid interactions with the Shaker voltage-gated potassium channel. PLoS Comput Biol 12, e1004704.

Yehuda, S. \& Carasso, R.L. 1993. Modulation of learning, pain thresholds, and thermoregulation in the rat by preparations of free purified $\alpha$-linolenic and linoleic acids: Determination of the optimal $\omega 3$-to- $\omega 6$ ratio. Proc Natl Acad Sci U S A 90, 10345-10349.

Young, C., Gean, P.W., Chiou, L.C. \& Shen, Y.Z. 2000. Docosahexaenoic acid inhibits synaptic transmission and epileptiform activity in the rat hippocampus. Synapse 37, 9094. 
Yu, S.P. 1995. Roles of arachidonic acid, lipoxygenases and phosphatases in calciumdependent modulation of M-current in bullfrog sympathetic neurons. J Physiol 487, 797-811.

Zheng, Q., Fang, D., Liu, M., Cai, J., Wan, Y., Han, J.S. \& Xing, G.G. 2013. Suppression of $\mathrm{KCNQ} / \mathrm{M}(\mathrm{Kv} 7)$ potassium channels in dorsal root ganglion neurons contributes to the development of bone cancer pain in a rat model. Pain 154, 434-448. 


\section{Figure legends}

Figure 1. Effect of DHA on DRG neurons. (a) Structure of fatty acids and analogues tested.

(b) Representative effect of $30 \mu \mathrm{M}$ DHA and $10 \mu \mathrm{M}$ XE991 on resting $V_{\mathrm{m}}$ in a DRG neuron. Dashed line denotes baseline. (c) Representative effect of DHA on the stimulation current needed to evoke action potentials. The stimulation pulse starts at $\mathrm{t}=2 \mathrm{~ms}$ and continues for 50 ms. Control (blue), $30 \mu \mathrm{M}$ DHA (red).

\section{Figure 2. Effect of DHA and EPA on the $h_{V} 7.2 / 3$ channel expressed in Xenopus} oocytes. (a-b) $70 \mu \mathrm{M}$ DHA shifted the $G(V)$ curve of the $\mathrm{hK}_{\mathrm{V}} 7.2 / 3$ channel in negative direction along the voltage axis. Control (०), DHA (•). Arrows in (a) denote currents at -40 $\mathrm{mV}$. The dashed curve in (b) is the control curve shifted $-9.6 \mathrm{mV}$. Inset shows time course of DHA wash-in at $-30 \mathrm{mV}$ (steady-state currents at the end of the test pulse). Application of DHA starts at the arrow. (c) Concentration dependence of DHA-induced $\Delta V_{1 / 2}$. Continuous line is best fit to Eq. 2. $\Delta V_{1 / 2 \max }=-11.0 \mathrm{mV}, c_{1 / 2}=10.2 \mu \mathrm{M}, n_{\mathrm{H}}=1.1$. Mean \pm SEM. $n=3-5$. (d-e) $70 \mu \mathrm{M}$ ALA or EPA shifted the $G(V)$ curve of the $\mathrm{hK}_{\mathrm{V}} 7.2 / 3$ channel in negative direction along the voltage axis. Control (०), ALA/EPA $(\bullet)$. Dashed curves are the control curves shifted by -8.0 and $-10.3 \mathrm{mV}$, respectively.

Figure 3. Importance of the carboxyl charge and the acyl tail for PUFA effects. (a-b) 70 $\mu \mathrm{M}$ DHA methyl ester (DHA-me) did not induce $G(V)$ shift of the $\mathrm{hK}_{\mathrm{V}} 7.2 / 3$ channel expressed in Xenopus oocytes. Control (०), DHA-me (•).Arrows denote currents at $-40 \mathrm{mV}$. (c-e) $\mathrm{pH}$ dependence of DHA effect. Insets in (c) and (d) illustrate how different $\mathrm{pH}$ affect protonation of DHA. Red spheres illustrate protons. Dashed curve in (c) is control curve shifted by $-18 \mathrm{mV}$. Continuous line in (e) is best fit of Eq. 2 data for $70 \mu \mathrm{M}$ DHA in different pH: $\Delta V_{1 / 2 \max }=-24.4 \mathrm{mV}, c_{1 / 2}=3 \times 10^{-8} \mathrm{M}=\mathrm{pH} 7.5, n_{\mathrm{H}}=1.6$. Mean \pm SEM. $n=3-8 .(\mathrm{f}-\mathrm{g})$ 
$70 \mu \mathrm{M}$ oleic acid (OA) did not induce $G(V)$ shift of the $\mathrm{hK}_{\mathrm{V}} 7.2 / 3$ channel expressed in Xenopus oocytes. Control (०), OA (•). Arrows denote currents at $-40 \mathrm{mV}$.

Figure 4. Impact of KCNE co-expression on DHA effects. (a-b) $70 \mu \mathrm{M}$ DHA shifted the $G(V)$ curve of the $\mathrm{hK}_{\mathrm{V}} 7.2 / 3+\mathrm{hKCNE} 1$ channel in negative direction along the voltage axis. Control (०), DHA (•). Arrows denote currents at $-50 \mathrm{mV}$. The dashed curve in $(\mathrm{b})$ is the control curve shifted by $-10.0 \mathrm{mV}$. (c-d) $70 \mu \mathrm{M}$ DHA shifted the $G(V)$ curve of the $\mathrm{hK}_{\mathrm{V}} 7.2 / 3+\mathrm{hKCNE} 2 \mathrm{channel}$ in negative direction along the voltage axis. Control (o), DHA $(\bullet)$. Arrows denote currents at $-50 \mathrm{mV}$. The dashed curve in (d) is the control curve shifted by $-6.0 \mathrm{mV}$. 
Figure 1

(a)

DHA

ALA

EPA

$\mathrm{OA}$

DHA-me

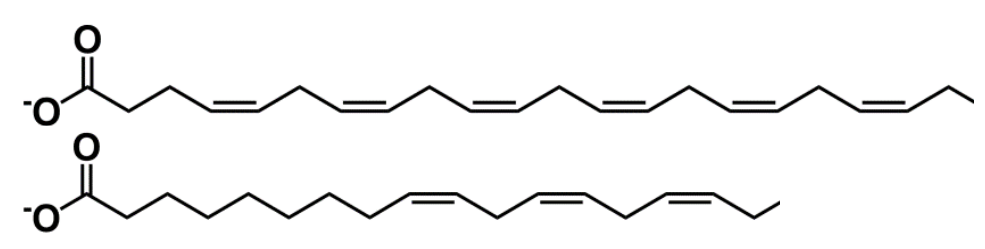

(c)
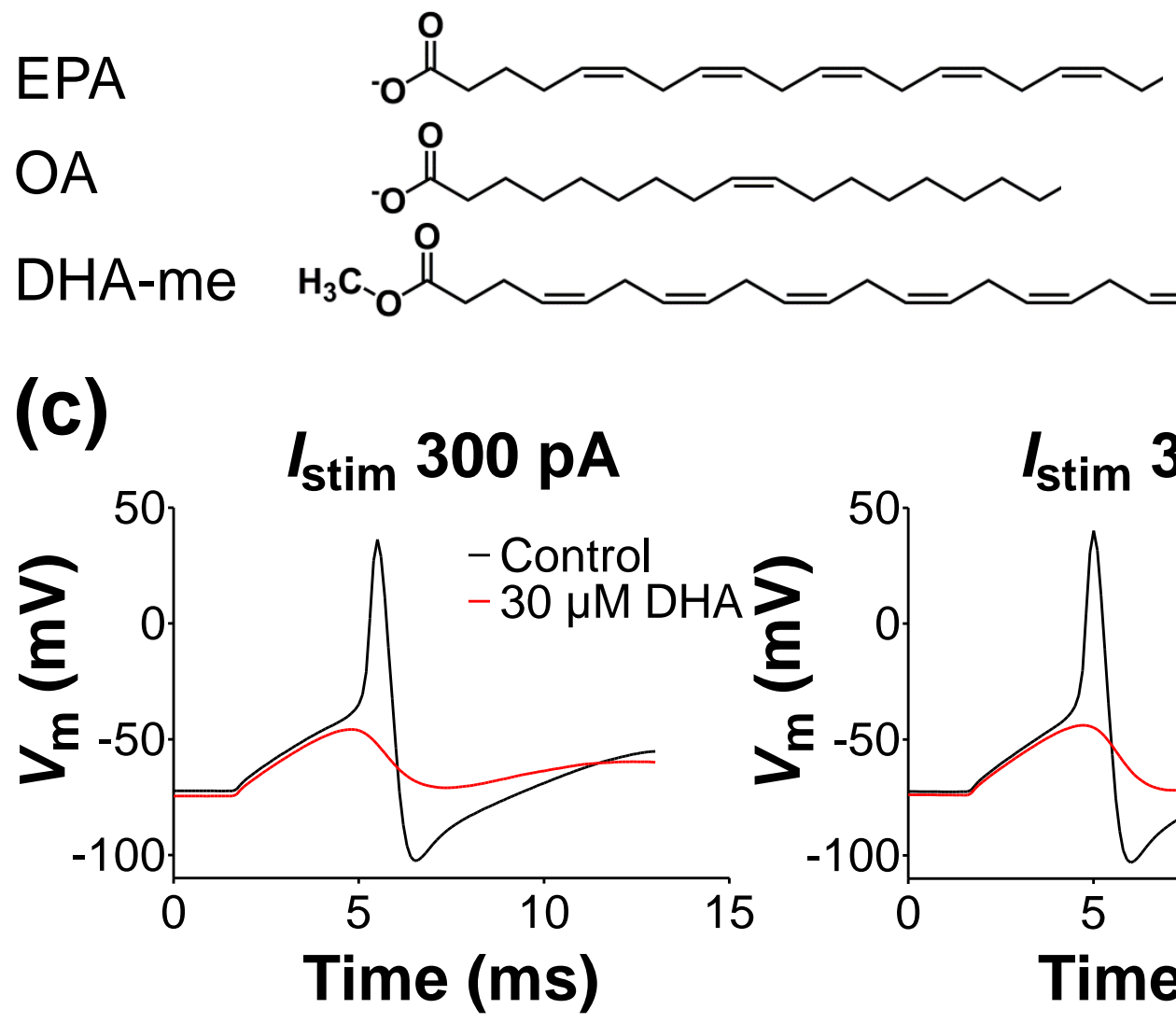

(b)

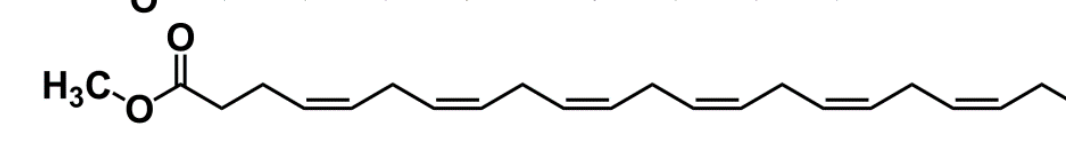

$I_{\text {stim }} 300$ pA $\quad I_{\text {stim }} 320$ pA

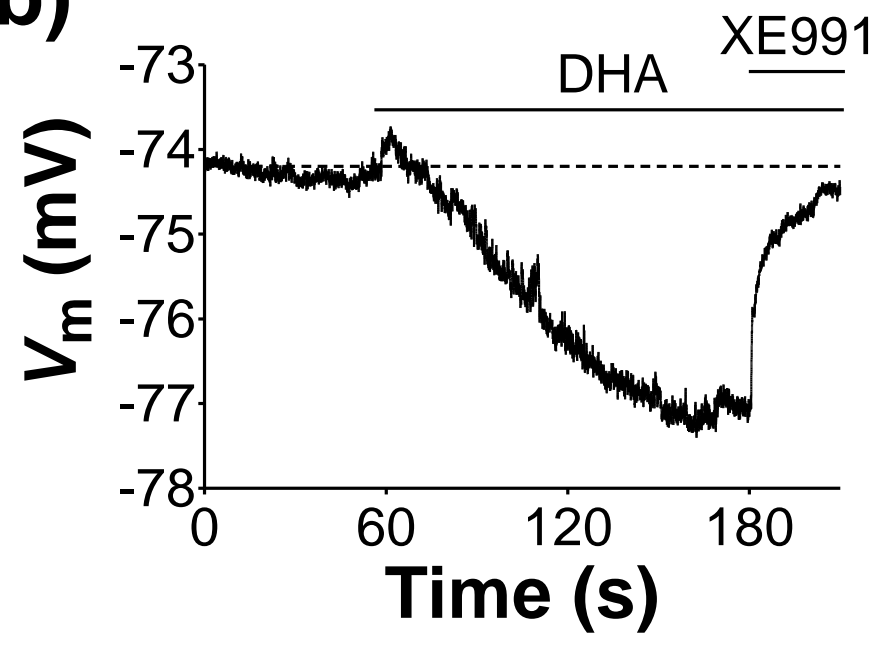

Time (s)

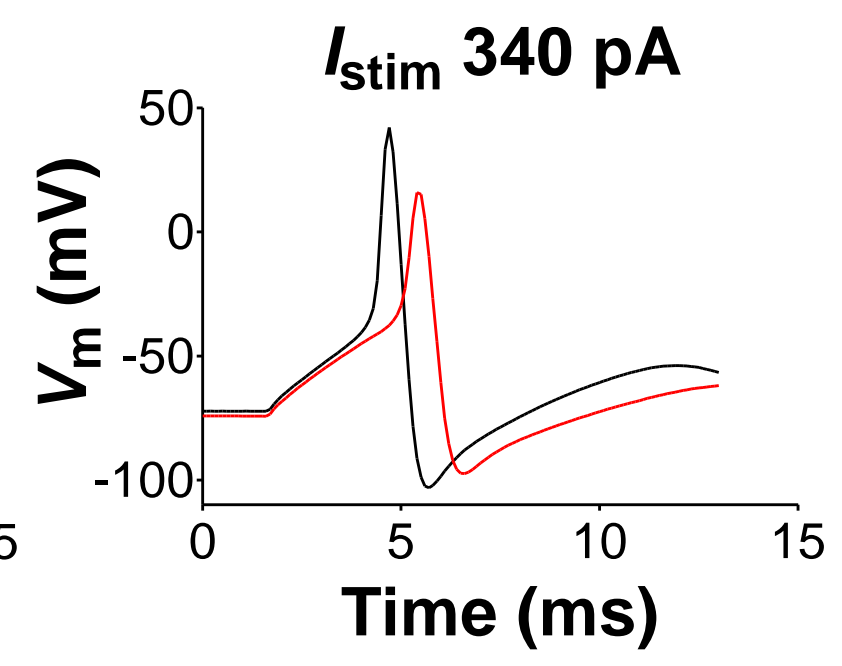


Figure 4

(a)

+KCNE1

Control

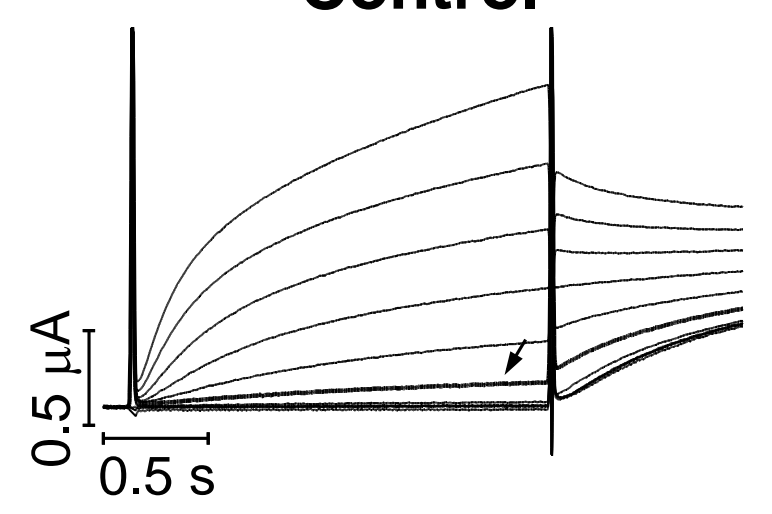

(c)

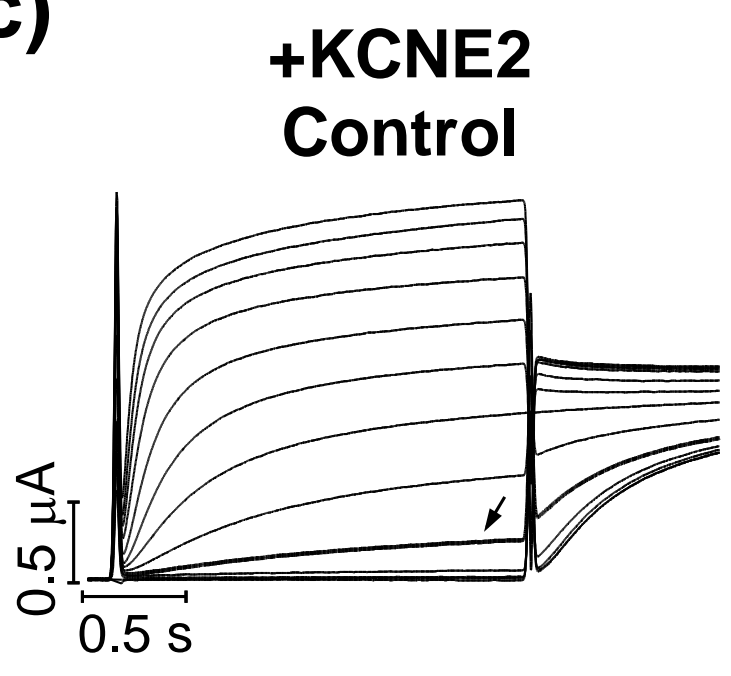

+KCNE1

$70 \mu \mathrm{M}$ DHA

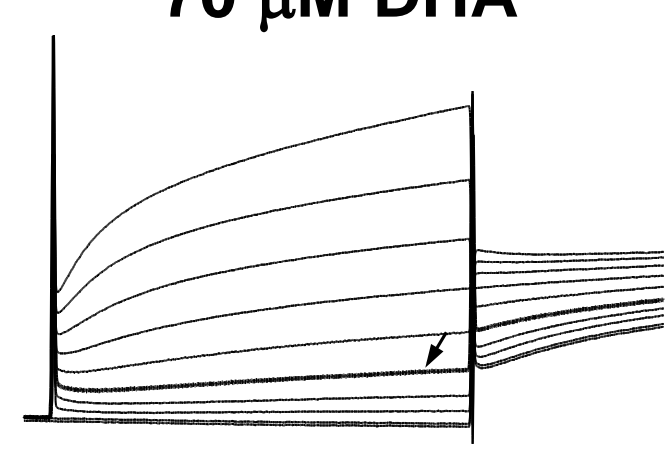

+KCNE2

$70 \mu \mathrm{M}$ DHA

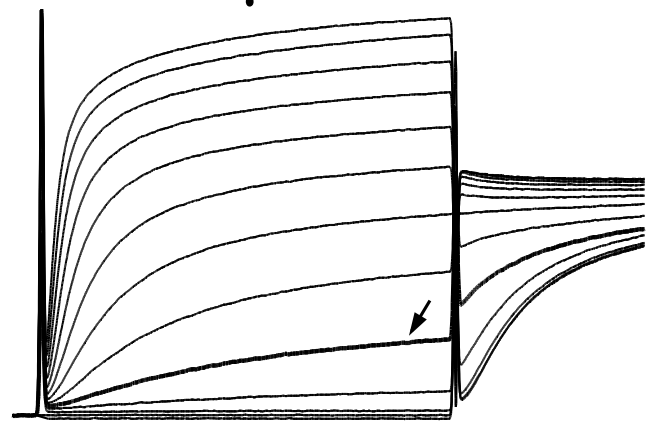

(b)

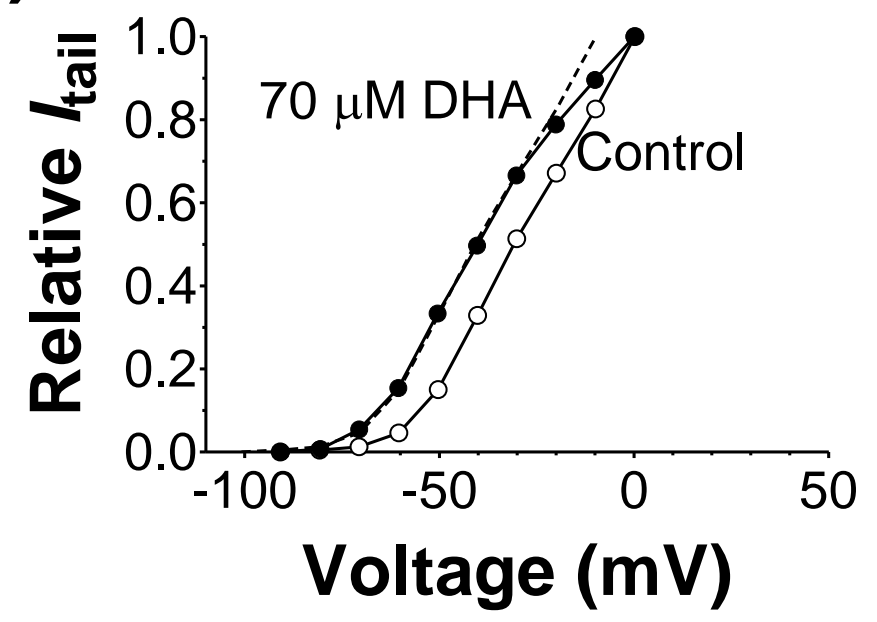

(d)

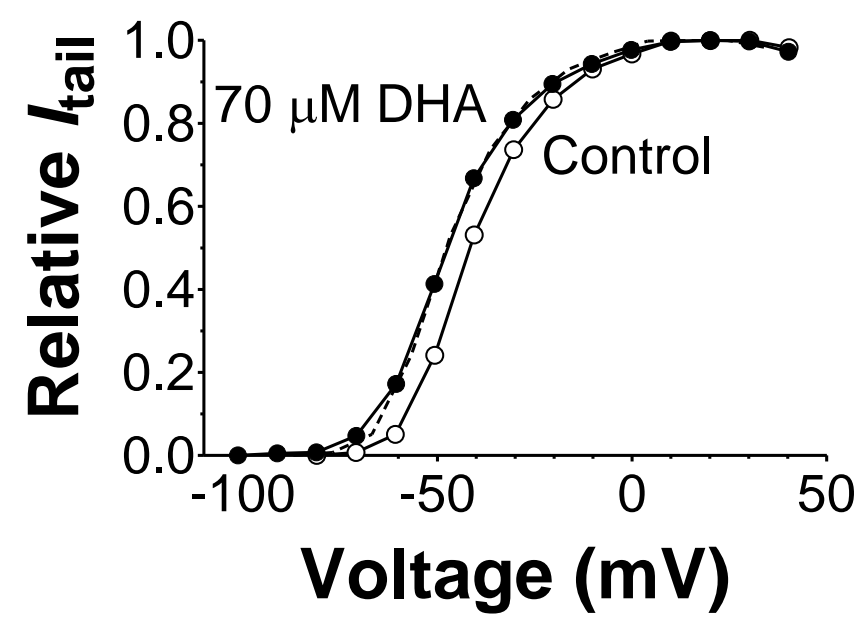

